\title{
Riparian habitat assessment tool for Lebanese rivers (RiHAT): case study Ibrahim River
}

\author{
Maya Abboud', Jala Makhzoumi², C. Clubbe', R. Zurayk,, \\ S. Jury ${ }^{4}$, S. N. Talhouk ${ }^{1,2}$
}

I Ibsar, nature conservation center for sustainable futures - American University of Beirut, P.O. Box 11-0236 Beirut, Lebanon 2 Department of Landscape Design and Ecosystem Management, Faculty of Agricultural and Food Sciences, American University of Beirut, P.O.Box: 11-0236, Beirut, Lebanon 3 Royal Botanic Gardens, Kew, Richmond Surrey, TW9 3AB, UK 4 Centre for Plant Diversity and Systematics, Plant Science Laboratories, The University of Reading, Whiteknights, P.O. Box 221, Reading, RG6 6AS, UK

Corresponding author: S. N. Talhouk(ntsalma@aub.edu.lb)

Academic editor: Josef Settele | Received 31 March 2011 | Accepted 19 December 2011 | Published 17 October 2012

Citation: Abboud M, Makhzoumi J, Clubbe C, Zurayk R, Jury S, Talhouk SN (2012) Riparian habitat assessment tool for Lebanese rivers (RiHAT): case study Ibrahim River. BioRisk 7: 99-116. doi: 10.3897/biorisk.7.1331

\begin{abstract}
Biodiversity conservation in Lebanon ought to be guided by practical assessment tools in order to promote conservation efforts amid destructive and profit driven urban and industrial expansion. The challenge for national conservation scientists, however, is to develop such tools while reconciling between scientific 'rigor' and pressing national realities. Those include rapid habitat loss, limited human and financial resources, and the fact that biodiversity is a low national priority compared to other social, political, and economic issues. It is in this context that we propose a rapid management strategy guide based on a habitat assessment tool for riparian ecosystems (which are typically threatened in Lebanon). The proposed riparian habitat assessment tool (RiHAT) consists of a habitat condition index based on twelve indicators grouped under two attributes, floristic and landscape.
\end{abstract}

\section{Keywords}

Riparian assessment, habitat condition index, riparian vegetation, Mediterranean river management

\section{Introduction}

Located along the Eastern shores of the Mediterranean, the Lebanese natural landscape is unique in its immediate context in that it is mostly mountainous $(3090 \mathrm{~m}$ highest peak), houses 38 permanent and seasonal flow rivers, and is considered a global

Copyright Maya Abboud et al. This is an open access article distributed under the terms of the Creative Commons Attribution License 3.0 (CC-BY), which permits unrestricted use, distribution, and reproduction in any medium, provided the original author and source are credited. 
hotspot with an estimated floristic richness of 2,600 vascular plant species of which 311 are endemic (12\%) (Davis et al.1994; Myers et al. 2000; Wolz 1998). Given the limited water resources of the East Mediterranean and Middle East regions, floristic assessment and conservation along coastal rivers deserve attention especially when the ecological status of many rivers remains largely undocumented. Furthermore, rivers stretching into coastal areas are not only subjected to industrial and tourism activities but are also threatened by urban expansion with a large percent of the population residing in that zone (Ministry of Environment-Lebanon 2001).

The Ibrahim River in Lebanon, exemplifies Mediterranean riparian landscapes that have been subjected to human induced modifications for years, and consists of habitats that have been molded by the interplay of natural features coupled with cultural, social and economic influences. The River is known for its historic and cultural value as it lies in the ancient Adonis valley. During pagan times, a pilgrimage road ran along the river towards its source (Fitzpatrick et al. 2001). The river is also associated with ancient Greek myths as it represents the scene of the tragic love story of Venus (Astarte) and Adonis. Other archeological interests along the river include three Roman temples of Yanuh, Aqoura and Afqa, the remains of a Roman aqueduct and an Ottoman bridge built in 1806 close to the estuary (Ministry of Agriculture 1999). Recently, the intensity and diversity of uses have placed the Ibrahim riparian landscape under threat from channel modification, pollution from agricultural contamination, sewage discharge and recreational pressures.

Assessment and management recommendations for conservation of floral diversity in rivers such as the Ibrahim River, which demonstrates co-evolution between people and natural resources, need to take these into consideration various perspectives including socio-cultural and ecological contexts of riparian ecosystems.

Assessments of riparian ecosystems were initially based on a limited number of biological, biochemical, or physiochemical components; these proved to be late and insufficient in preventing damage due to the complex nature of ecosystems (Maddock 1999). Subsequent models based on complex river assessment studies ranged from those focusing primarily on vegetation to those focusing on physical structures and hydrological regimes with some studies integrating floristic and a multitude of abiotic parameters (Kleynhans et al. 1999; Jansen and Robertson 2001; Rossi and Kuitunen 1996; Kasyak 1996; EPA 1996; TNRCC 1999; Russel et al. 1997; USDI 1998; Raven et al. 1998; Davenport et al. 2004; ARHMS 2002; Oliveira and Cortes 2005; Barbour et al. 1999; Wilhelm et al. 2005; Stromberg et al. 2006; An et al. 2002). Most proposed models however failed to incorporate a socio-cultural dimension which addresses evolving history and use of riparian habitats, and which constitutes an important aspect for policy and decision makers. The objective of this study was to develop an assessment tool that takes together floristic and landscape attributes to guide management actions by offering a flexible foundation for conservation assessments in dynamic, multiple-use riparian landscapes such as Lebanon. 


\section{Methods}

A four step approach was adopted to develop the RiHAT: (i) a list of parameters/indicators used in biodiversity assessment and management tools was compiled from the literature, (ii) Ibrahim River was used as a case study to develop additional indicators (primarily those related to floristic attributes) and for field testing the applicability of selected indicators, (iii) a method of scoring was developed for each selected and/or developed indicator to attain an overall integrated index, (iv) management actions were developed based on the different values obtained in the integrated index.

\section{Description of the case study river}

Ibrahim River was selected as a case study to develop a RiHAT for Lebanon. The river lies in a typical Mediterranean climate, with moderately cold-wet winters, warm-dry summers, and an average precipitation of 1,300 $\mathrm{mm}$. Located $20 \mathrm{~km}$ north of Beirut, Ibrahim River extends over $30 \mathrm{~km}$ from its source in Afqa to the Mediterranean Sea (Figure 1), and serves as an important water resource for the country with an average yearly flow rate of $10 \mathrm{~m}^{3} / \mathrm{s}$ (Fitzpatrick et al. 2001). The major water sources into the river include the Afqa spring, Nahr Roueiss tributary as well as 30 other smaller springs (Papazian 1981). Lined with sycamore trees and outcropping geological formations from the Jurassic to Cretaceous, the river lies at the bottom of a steep valley and lush mountainsides and experiences high relative humidity throughout the year (Papazian 1981).
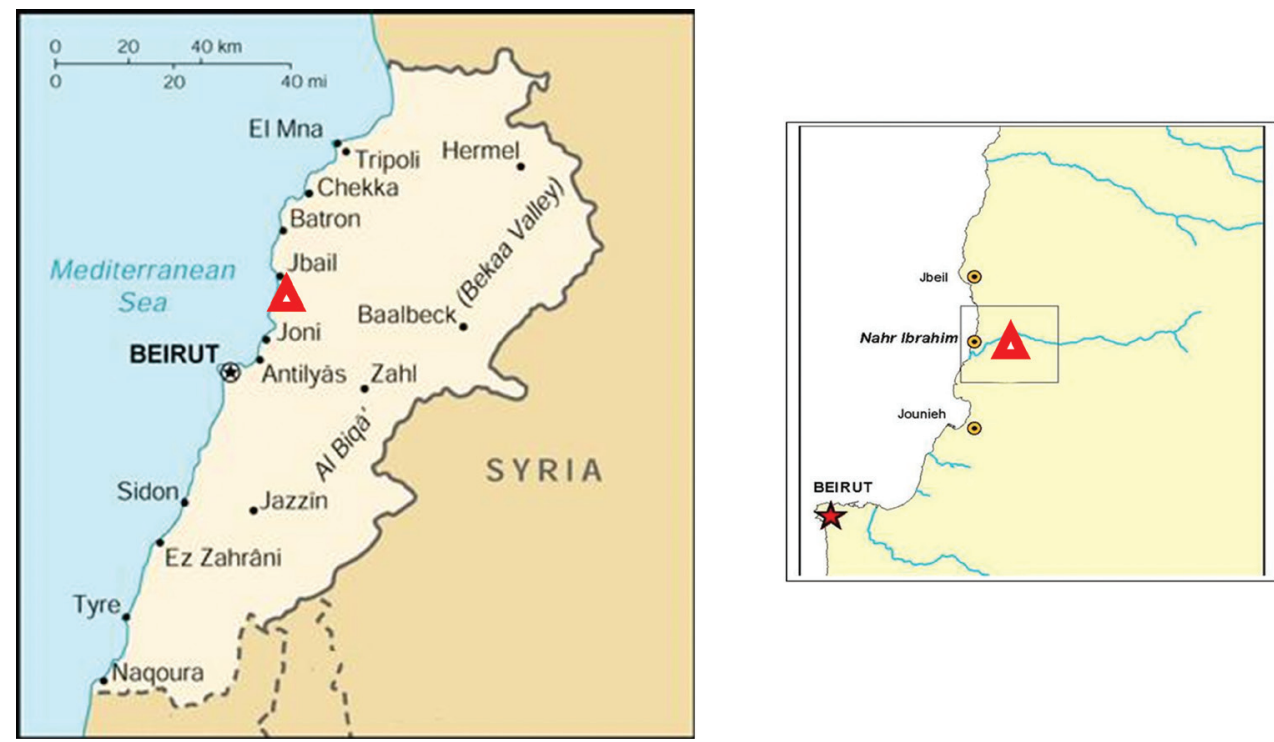

Figure I. Map locating Ibrahim River in Lebanon (adapted from the CIA's World Factbook map of Lebanon: https://www.cia.gov/library/publications/the-world-factbook/geos/le.html) 


\section{Selection of study area}

The coastal zone of Ibrahim River was defined for the purpose of this and other concurrent floristic assessment studies as the zone extending from the littoral inland to approximately $2.5 \mathrm{~km}$ or to an altitude of $500 \mathrm{~m}$ depending on the width of the coastal area taking into consideration site accessibility (Dagher 2001; Dardas 2000; Zahreddine 2001; El Hachem 2000). Accordingly, the study area was delineated at the beginning of field work as the $10 \mathrm{~km}$ stretch along the river starting from the estuary to the innermost location at an altitude of $240 \mathrm{~m}$ and beyond which lies an inaccessible zone due to the existence of an electrical power plant.

\section{Field investigation of study area}

Sites for data collection were systematically selected at $500 \mathrm{~m}$ intervals extending 50 $\mathrm{m}$ parallel to the river while the width of the site depended on the actual range of the bank, which averaged $3 \mathrm{~m}$. In total, 20 survey sites were selected for data recording covering both banks of the river. One of the sites was destroyed by the second collection trip and all the vegetation was cleared off the site for construction purposes and was therefore not included in the study.

\section{Development of the riparian habitat assessment tool}

Floristic attributes: A detailed survey of the vegetation was conducted through three sampling trips which were made at different seasons during the year in order to capture the entire range of vegetation. These periods, namely spring (April), summer (JuneJuly), and fall (October-November) were chosen in accordance to previous studies that determined time of peak vegetation (Dagher 2001).

Within each survey site, tree species were recorded and the number of trees per site counted. An understory species area curve was conducted for several survey sites, to determine the appropriate number of quadrats to include per site (Kent and Coker 1992). The results revealed that ten $1 \mathrm{~m}^{2}$ quadrats per site provided representative information of the site's flora. The quadrats were chosen via pacing using randomly generated binominals. Data recording for the understory consisted of preliminary field identification of species, taking voucher specimens for taxonomic identification purposes, and estimating vegetation cover for each species according to the BraunBlanquet cover scale (Kent and Coker 1992). To ensure the permanence of plots from which data were recorded, inconspicuous metal rods were inserted in the ground at the center of each plot and, at every visit a $0.6 \mathrm{~m}$ rope was attached to the rod and used to delineate the circle within which data were recorded. The $0.6 \mathrm{~m}$ rope was used to achieve an approximate area of $1 \mathrm{~m}^{2}$, an area typically used to record the presence of herbaceous species (Thompson et al. 1998, Kent and Coker 1992). 
Taxonomic identification and nomenclature of specimens was based on published local floras and an updated coastal checklist (Hepper and Zahreddine 2000; Mouterde 1970; Post and Dinsmore 1933). Identified species were categorized as riparian specific, generalist, weed, invasive, or endemic. Riparian species were determined by subtractive analysis combining information from published local flora and other sources reporting plant species recorded in various coastal vegetation communities and those present along water courses (Dagher 2001; Hepper pers. comm.; Khouzami et al. 1996; Mouterde 1970; Post and Dinsmore 1933). Invasive species were characterized based on data published by Le Floc'H (1991). Weeds were considered as those species that are not naturally associated with plant communities but are typically abundant in disturbed habitats (Radosevich et al. 1997). Species were categorized in this study as weed based on three references: (i) published information on the most common weeds in Lebanon (Edgecombe 1970), (ii) an updated list of the 60 most common weed species in Lebanon (Professor M. Haidar, pers. comm.) and (iii) by cross referencing the list with the world's 76 worst weed species (Radosevich et al. 1997). Endemic species were identified by referring to published local flora and the national report on the biological diversity in Lebanon (Post and Dinsmore 1933; Mouterde 1970; Khouzami et al. 1996). Taxonomic identification was limited by human and financial resources and a cutoff point was designated in which three sites with more than $30 \%$ unidentified species were excluded from the analyses leaving seventeen sites. This decision was taken considering that taxonomic deficiency is a prevalent issue and that this limitation often affects the progress of conservation decisions. First coined by Sir Bob May the "taxonomic impediment" refers to the combination of inadequate taxonomic knowledge, the shortage of taxonomists, and the inadequacy of sampling, collections, human resources and infrastructure.

Landscape attributes: Most published models rely on indicators to quantify improvement or degradation of habitat quality and to anticipate change that could affect a particular habitat resource (Bundi et al. 2000). A list of 130 published indicators/ parameters were used as baseline information for the development of the RiHAT according to their applicability to the study area (Kleynhans et al. 1999; Jansen and Robertson 2001; Olson and Harris 1997; Rossi and Kuitunen 1996; Kasyak 1996; EPA 1996; Tiner et al. 2000; Verdonschot 2000; TNRCC 1999; O’Neill et al. 1997; Russel et al. 1997; USDI 1998; Raven et al. 1998; Davenport et al. 2004; ARHMS 2002; Ladson et al. 1999; Oliveira and Cortes 2005; Barbour et al. 1999; Wilhelm et al. 2005; Stromberg et al. 2006; An et al. 2002). Criteria considered when developing indicators for our assessment tool targeted the generation of information that is ecologically meaningful, sensitive to stress and disturbances, reproducible in the Lebanese context, cost effective and effectively communicated to non-technical managers and the public (Barbour et al. 2000). Field investigations were also conducted to guide the process of developing landscape attributes. During visits to survey sites, field inspections consisted of recording environmental quality and visual characters to reflect the status and land use functions. A least-impacted reference site (survey site 3) located in the upper region of the study area was considered during the development of attributes 
for benchmarking against acceptable or desirable ecological conditions (Hughes 1995; Simon et al. 2001). Meetings were subsequently held to develop indicators that would convey a tangible message to the public and decision makers who are not necessarily interested or concerned with scientific justifications for conservation and management. As such, landscape indicators that were developed and incorporated into the habitat assessment tool were based on the assumption that the tool must recognize limitations, namely that biodiversity conservation along coastal Lebanese rivers is perceived secondary to the cultural and social services the rivers provides.

\section{Data analysis}

Flora richness was calculated as the total number of species per site recorded in one year. Site diversity was measured by the Shannon-Wiener diversity index (H') (Kent and Coker 1992). Similarity among the sites in terms of species composition was determined by the Sorensen index (Sorensen 1948). Correlation analysis was based on Spearman coefficient.

\section{Results}

\section{Floristic attributes of RiHAT}

The vegetation survey of Ibrahim River produced a collection of 367 plant specimens that were considered for the purpose of this study as different species. The best-represented families were Asteraceae, Poaceae, Fabaceae, Lamiaceae and Apiaceae, which contributed to $38 \%$ of the recorded flora while the rest of the species belong to 25 different families. Categorization of the identified species into endemic, riparian, weed, and invasive indicated the presence of 2 endemics (Origanum ehrenbengii and Papaver umbonatum), 13 riparian specific and 2 riparian generalist, 39 weed, and 3 reported Mediterranean invasive species. In addition, 15 species were identified to have medicinal value. Many species belonged to more than one category as follows: 11 medicinal and weeds, 4 medicinal and riparian general, 4 medicinal and riparian specific, 2 riparian specific and weeds, 1 riparian general and Mediterranean invasive and 1 medicinal and Mediterranean invasive. Table 1 provides a summary of vegetation survey across the 20 survey sites.

The measure of plant species richness and number of trees species per site did not reflect perceived visual changes downstream towards the estuary from semi-natural undisturbed sites to significantly modified and exploited sites. Richness, which included number of species assessed over a year's data recording, and averaged 34 species per 200 $\mathrm{m}^{2}$ site, was not significantly correlated with distance from estuary $\left(\mathrm{R}^{2}=0.25\right)$ which provided readily noticeable visual site differences. This was also the case with the number of recorded tree species per site which varied between 2 and 7 species $\left(R^{2}=0.06\right)$. 
Table I. Description and number of collected plant species in study area along Ibrahim River

\begin{tabular}{|c|c|c|c|c|c|c|c|c|c|c|c|c|c|c|c|c|c|c|c|c|}
\hline Site & 1 & 2 & 3 & 4 & 5 & 6 & 7 & 8 & 9 & 10 & 11 & 12 & 13 & 14 & 15 & 16 & 17 & 18 & 19 & 20 \\
\hline$\overline{\text { and }}$ & 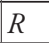 & $R$ & $R$ & $F$ & D & & $S N$ & $S N$ & $R$ & $S N$ & $S N$ & & & $J^{11}$ & $A$ & 114 & $S N$ & $A$ & & $A$ \\
\hline & & & & & & & 7 & & + & & 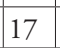 & 26 & & 37 & 0 & 49 & 3 & 50 & 8 & 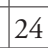 \\
\hline & & 0 & 13 & 0 & 5 & & 3 & 9 & 14 & 3 & & 4 & 32 & 18 & 15 & 10 & 6 & 12 & 17 & 3 \\
\hline & & 0 & 25 & 0 & 23 & & 11 & 25 & 25 & 1 & ) & 15 & 48 & 49 & 38 & 20 & 18 & 4 & 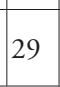 & 13 \\
\hline & 3 & 3 & 4 & 7 & 4 & a & & & & 6 & & 2 & & 5 & & & & & & 0 \\
\hline & 4 & 4 & 4 & 5 & 1 & S & 2 & 2 & O & P & 4 & 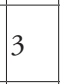 & 3 & 3 & $\left.\right|^{2}$ & 5 & 2 & 6 & 5 & 1 \\
\hline & 3 & 1 & (1) & -1 & 0 & & 2 & 4 & 1 & 0 & & | & 5 & 0 & 10 & 14 & r & 20 & 23 & 12 \\
\hline 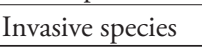 & 3 & 1 & 3 & 1 & 0 & $J^{2}$ & 3 & 3 & 2 & 1 & & 1 & 8 & 6 & 3 & 6 & 6 & 6 & 5 & 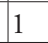 \\
\hline
\end{tabular}

* A: agriculture, I: industrial, R: recreation, $\mathrm{SN}$ : semi-natural

** Sites with more than $30 \%$ unidentified species were excluded from the study

The results also revealed that more than half of all identified species were present in only one of the 20 collection sites while only few species were encountered across several sites. This was supported by low similarity indices that ranged between 0.05 to 0.46 Isor (Sorensen's similarity coefficient) between sites, even visually similar ones.

Further analysis of the floristic composition revealed statistically significant trends defined by polynomial relationships for both weeds and invasive species with coefficients of determination for weeds $\left(\mathrm{R}^{2}=0.77, \mathrm{p}=<0.01\right)$ and for invasive species as $\left(\mathrm{R}^{2}=0.68, \mathrm{p}<001\right)$ in relation to distance from estuary as shown in Figure 2. In contrast riparian specific species did not vary greatly among sites $\left(R^{2}=0.13\right)$.

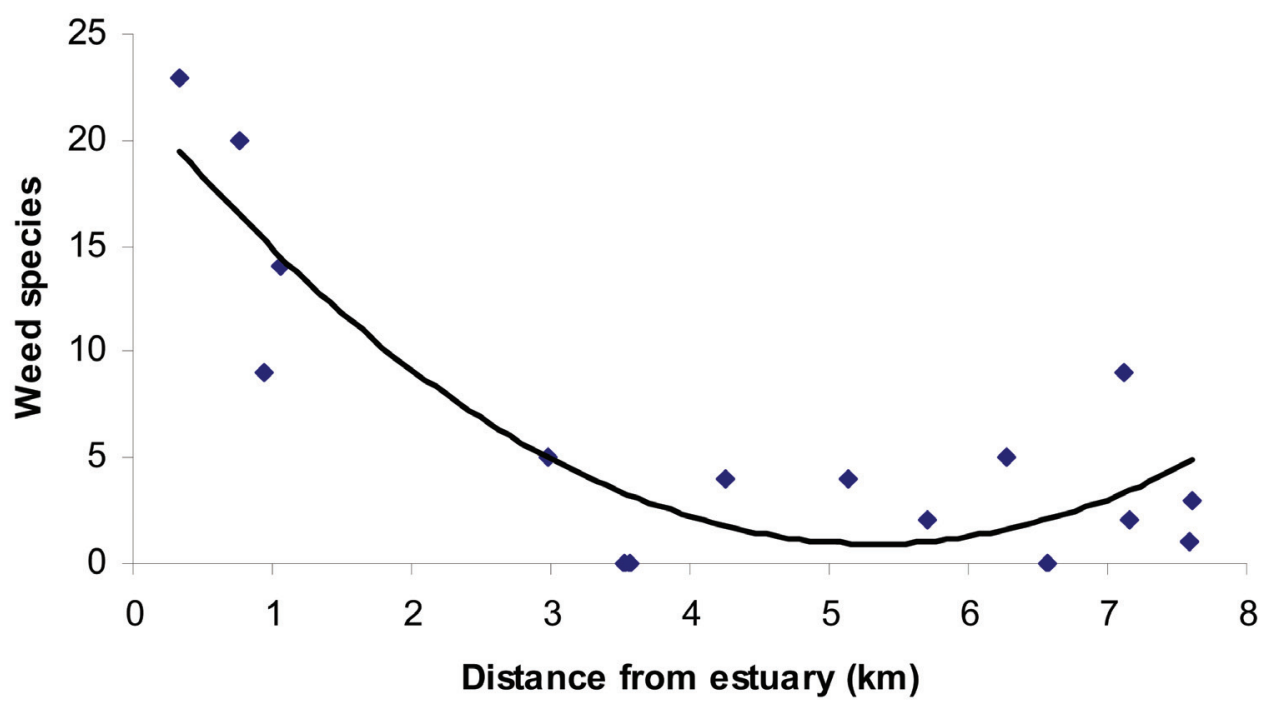

Figure 2a. Relationship between number of weed species and distance from estuary in study area along Ibrahim River $\left(y=0.7472 x^{2}-7.9513 x+22.079 ; R^{2} 0.77 ; P<.01\right)$ 


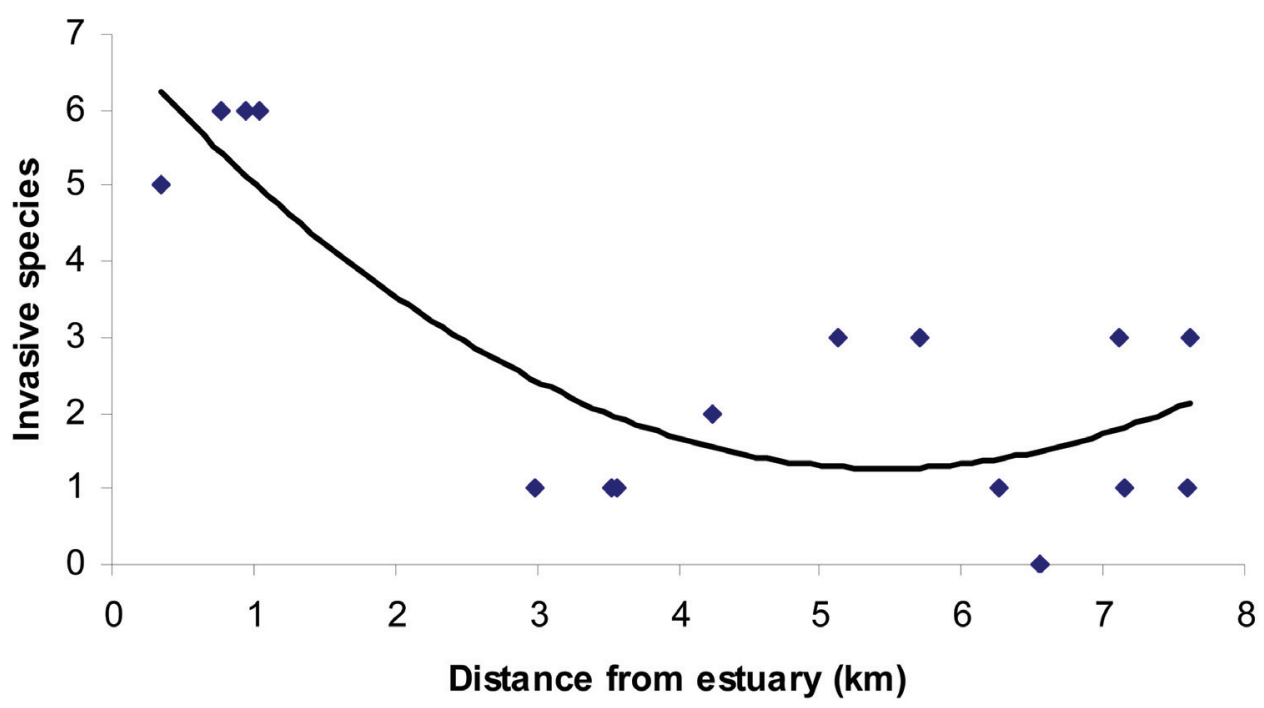

Figure 2b. Relationship between number of invasive species and distance from estuary in study area along Ibrahim River $\left(y=0.1902 x^{2}-2.0772 x+6.935 ; R^{2} 0.68 ; P<.01\right)$

Based on these findings the floristic attribute adopted for RiHAT includes six indicators (Table 2): (i) species distribution which takes into consideration reported distribution ranges and gives priority to sites with a majority of species with natural distribution limited to the eastern Mediterranean region, (ii) conservation status which is based on IUCN categories and gives priority to sites harboring threatened species, (iii) species richness which is based on the number of recorded species and priority is given to high species richness, (iv) percent canopy cover which is adapted from Jansen and Robertson (2001) and gives priority to partially shaded areas, (v) invasive species which is based on the number of recorded Mediterranean invasive species and priority is given to sites with no invasive species and (vi) percent weed species which is considered in terms of percent weedy species among total recorded species and priority is given to sites with low presence of weedy species.

Table 2. Riparian Habitat Assessment Tool developed for Ibrahim River: Floristic attributes

Indicator ${ }^{I}:$ Species distribution

Score: Large range (1), Medium range (2), Limited range (3)

Method of Scoring: Large range: Majority of species have a global distribution range; Medium range:

Majority of species have a natural distribution range limited to the Mediterranean basin; Limited range: Majority of species have a natural distribution range limited to the Eastern Mediterranean basin

Indicator ${ }^{2}$ : Conservation Status

Score: Number of species globally threatened: Two or more (3), One (2), None (1)

Method of Scoring: Based on IUCN (2000) categories which include critically endangered, endangered, and vulnerable

Indicator: Species Richness

Score: High (3), Medium (2), Low (1)

Method of Scoring: High: >48, Medium: 21-48, Low: $<21$ 


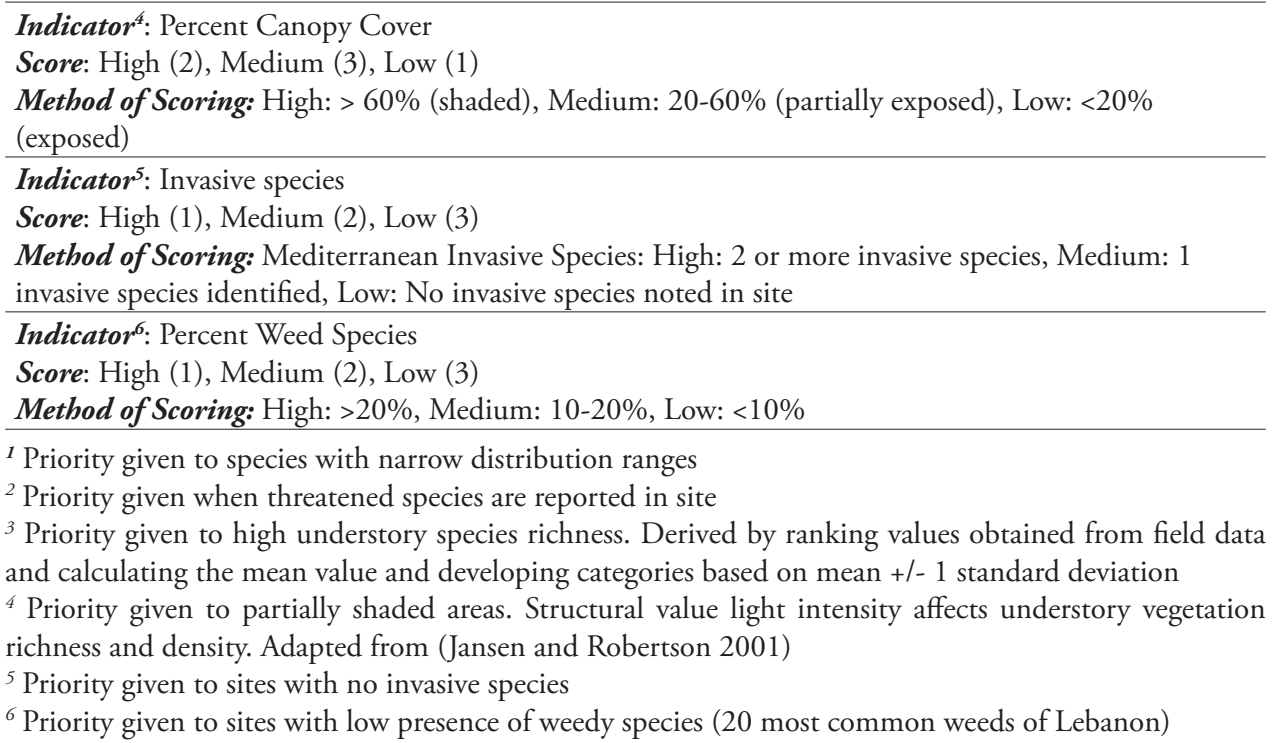

\title{
Landscape attributes of RiHAT
}

The proposed landscape attribute consists of six indicators including (Table 3): (i) bank erosion and priority is given to sites of low erosion which promotes vegetation stability, (ii) recovery potential includes a set of scorable questions that aim at determining the nature of disturbances and priority is given to more manageable, lower impact and temporary disturbances which render management efforts successful and long lasting, (iii) accessibility and priority is given to inaccessible sites that are naturally less disturbed with higher chances for conservation, (iv) environmental quality takes into consideration human refuse, vegetation disturbance, and water clarity and priority is given to undisturbed non polluted sites, (v) visual character is evaluated based on perceived 'naturalness' of the site and priority is given to sites with semi-natural overall appearance and (vi) cultural value takes into consideration the presence and proximity of archeological, historic, and/or religious sites and gives priority to sites near areas with cultural interest. The bank erosion indicator was derived directly from literature; the remaining five parameters were also derived from literature; however, their applicability was verified on-site to ensure that they are relevant to the case of Ibrahim River as well as other rivers systems in Lebanon.

Table 3. Riparian Habitat Assessment Tool developed for Ibrahim River: Landscape attributes

\author{
Indicator: Bank Erosion \\ Score: High (1), Medium (2), Low (3)

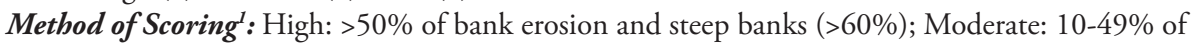 \\ bank erosion and bank angles (30-60\%); Low: $<10 \%$ of banks erosion and average bank angles $<30 \%$
}


Indicator: Recovery Potential

Score: High (3), Moderate (2), Low (1)

Method of Scoring ${ }^{2}$ : Disturbance local to the river (point source pollution) Yes: 1; No: 0; Disturbance temporary Yes: 1; No: 0; Disturbance can be eliminated Yes: 1; No: 0; Will recovery occur naturally if the disturbance is removed Yes: 1 ; No: 0

Three Yes = High, one to two Yes = Moderate; zero Yes = Low

Indicator: Accessibility

Score: Easy (1), Medium (2), Difficult (3)

Method of Scoring 3 : Easy: Site is readily accessible from the roadside; significant evidence of human activities. Medium: Stream segment is relatively close to road but not immediately accessible nor easily seen therefore requires some hiking to reach river bank; some evidence of human activity. Difficult: Stream segment is either far from roadside and requires an extended hike or site is not accessible requiring a strenuous hike down to reach site sometimes even crossing the stream; little or no evidence of human activity

Indicator: Environmental Quality

Score: Optimal (3), Sub-optimal (2), Poor (1)

Method of Scoring ${ }^{4}$ : Optimal: Little or no evidence of human refuse present, vegetation appears essentially undisturbed and water clarity may be slightly turbid; Sub-optimal: Refuse present in moderate amounts, and/or channelization of water present and/or minor disturbance to vegetation and water clarity may be turbid or discolored; Poor: Human refuse abundant and unsightly and/ or extensive unnatural channelization and/or highly disturbed vegetation, water clarity turbid or discolored

Indicator: Visual Character

Score: Semi-Natural (3), Agriculture (2), Built (1)

Method of Scoring 5 : Semi-Natural: Native trees and vegetation dominates. Site has retains its natural character. Agriculture: Cultivation, plantation, terraces predominantly replaced the natural vegetation. Built: Urban expansion (residential, recreational and industrial structures) has marginalized natural vegetation.

Indicator: Cultural Value

Score: High (3), Medium (2), Low (1)

Method of Scoring : High: Site within close proximity of valuable archeological, historic, and/or religious interests; Medium: Site close to archeological, historic and/or religious of minor interests or far from valuable ones. Low: No archeological, historic, and/or religious interests near site

1 Priority given to low erosion which promotes vegetation stability. Adapted from Stream Habitat Assessment Procedures (TNRCC 1999).

${ }^{2}$ Priority given to more manageable, lower impact and temporary disturbances, which in turn make management efforts more successful and long lasting. Takes into consideration complete destruction of habitat through the construction of urban structures.

${ }^{3}$ Priority given to inaccessible and therefore less disturbed sites with higher chances for conservation. The accessibility of sites determines the actual disturbances imposed on a site as well as affects future activities.

${ }^{4}$ Priority given to undisturbed non-polluted sites. The observed overall environmental quality of the site has significant implication for public acceptance and utilization of the site.

${ }^{5}$ Priority given to sites with semi-natural overall appearance. The visual character has tremendous bearing on conservation efforts as well as on people's perception of the river.

${ }^{6}$ Priority given to sites near areas with cultural interests. Even if this parameter does not directly affect stream flora, they reflect important human values associated with rivers. Historical, archeological, and religious interests along a river add an important dimension to the conservation potentials of a river and its associated habitat. 


\section{River management}

The sum of scores obtained from the two attributes and their respective indicators is intended to guide and prioritize management activities into one of four possible categories (Table 4): (i) conservation/protection, (ii) restoration to natural state, (iii) rehabilitation for new functions and (iv) intervention to limit further damage. The values assigned to each indicator were derived from data observation and were calibrated to achieve the greatest possible discrimination between prevailing observations. The scoring categories for each indicator were chosen on an arbitrary cardinal scoring scale ranging from 1-3.

High scoring sites (30-36) would warrant protection to conserve species of high ecological and conservation value. Medium scores (19-30) point to two possible venues namely restoration to natural state or rehabilitation to new functions depending on the relative scores of the two attributes. If the floristic attribute score is higher than the landscape attribute score, then restoration would be recommended because biodiversity conservation takes precedent even if the area offers a great potential for other uses. In the opposite scenario, restoration for new functions would be applied since the site is disturbed and endemic vegetation is virtually non-existent, however the site has retained a naturalness that is appealing for public use. Rivers receiving low scores (13-19) represent low species value, high weed composition, very modified and unhealthy habitat, and do not offer any potential for social utilization. In this case intervention is needed to limit further damage.

Table 4. Recommended actions based on the Riparian Habitat Assessment Tool developed for Ibrahim River area

\begin{tabular}{l|l|l|l}
\hline $\begin{array}{c}\text { Recommended } \\
\text { Action }\end{array}$ & $\begin{array}{l}\text { Habitat } \\
\text { Condition } \\
\text { Index Score }\end{array}$ & \multicolumn{1}{|c}{ Definition } & \multicolumn{1}{c}{ Justification } \\
\hline $\begin{array}{l}\text { Conservation/ } \\
\text { Protection }\end{array}$ & $30-36$ & $\begin{array}{l}\text { Minimize deleterious activities, } \\
\text { seal off fragile habitats, protect } \\
\text { species of high ecological and } \\
\text { conservation value }\end{array}$ & $\begin{array}{l}\text { Requires minimal human } \\
\text { intervention. A high score indicates } \\
\text { high species richness, diversity, } \\
\text { valuable conservation status, } \\
\text { low weed composition, healthy } \\
\text { habitat, high potential for recovery, } \\
\text { appealing for protection and offers } \\
\text { great potential for low impact } \\
\text { utilization. }\end{array}$ \\
\hline $\begin{array}{l}\text { Restoration to } \\
\text { natural state }\end{array}$ & $19-30$ & $\begin{array}{l}\text { Restoration: Returning some } \\
\text { degraded portions of landscape } \\
\text { to an improved and more natural } \\
\text { preexisting condition. Requires } \\
\text { more human intervention } \\
\text { in order to provide more } \\
\text { suitable habitats for the natural } \\
\text { vegetation to flourish while } \\
\text { controlling weeds and invasive } \\
\text { species; minimizing deleterious } \\
\text { activities, increasing habitats } \\
\text { connectivity and improving the } \\
\text { landscape character. }\end{array}$ & $\begin{array}{l}\text { Score from floristic attribute is } \\
\text { greater than the landscape score. } \\
\text { Indicates a decline in species } \\
\text { status and composition, habitat } \\
\text { modification, ecological resilience } \\
\text { is on a decline, landscape character } \\
\text { and quality is declining. Even if } \\
\text { the area offers a great potential } \\
\text { for other use, the high species } \\
\text { value demands more urgent focus } \\
\text { on restoring the site rather than } \\
\text { changing to other uses. }\end{array}$ \\
\hline
\end{tabular}




\begin{tabular}{|c|c|c|c|}
\hline $\begin{array}{l}\text { Rehabilitation } \\
\text { to new functions }\end{array}$ & & $\begin{array}{l}\text { Rehabilitation: Explore other } \\
\text { potential value and utilization } \\
\text { for the site depending on the } \\
\text { overall landscape character. } \\
\text { Conserving the flora is primarily } \\
\text { intended for cultural use } \\
\text { rather than strictly biodiversity } \\
\text { conservation. } \\
\text { New function include: Fishing, } \\
\text { canoeing, bird watching, } \\
\text { designated picnicking areas. }\end{array}$ & $\begin{array}{l}\text { Score from landscape attribute is } \\
\text { greater than the floristic attribute } \\
\text { scores. These sites are highly } \\
\text { disturbed, natural vegetation is } \\
\text { virtually non-existent; the habitat } \\
\text { quality cannot support healthy } \\
\text { vegetation and lose of its natural } \\
\text { resilience. However, its offer great } \\
\text { social value, as the site is appealing } \\
\text { for the public. }\end{array}$ \\
\hline $\begin{array}{l}\text { Intervention } \\
\text { to limit further } \\
\text { damage }\end{array}$ & 13-19 & $\begin{array}{l}\text { Minimize any deleterious } \\
\text { activities and pressures. Not } \\
\text { actively improve the situation } \\
\text { but rather remove the pressures } \\
\text { and allow nature to take its } \\
\text { course. }\end{array}$ & $\begin{array}{l}\text { In this scenario is is not possible } \\
\text { to reverse the damage done and } \\
\text { to go back to the natural state and } \\
\text { there is no potential for exploring } \\
\text { new functions. Site has low species } \\
\text { value, high weed composition, very } \\
\text { modified and unhealthy habitat, } \\
\text { unappealing for the pubic and does } \\
\text { not offer any potential for social } \\
\text { utilization. }\end{array}$ \\
\hline
\end{tabular}

\section{Discussion}

Early attempts at river classification reflected the perception of a river as a longitudinal continuum from source to mouth. In the last three decades, river habitat classification systems have increasingly adopted a hierarchical structure that includes many or all aspects within a geographic context whether it being a section, network or catchment (Davenport et al. 2004). Warren (1979) produced one of the first attempts, defining 11 spatial units, from the regional scale $\left(>10 \mathrm{~km}^{2}\right)$ to the microhabitat $\left(<1 \mathrm{~m}^{2}\right)$, using five key variables: substrate, climate, water chemistry, biota and culture. To provide a more integrated approach to channel assessment, habitat surveys shifted to include both the geomorphologic characteristics and the ecological composition of the channel as well as the surrounding riparian zone.

The importance of riparian flora far exceeds the minor proportion of the land base because the extent and structure of riparian vegetation provide a wildlife refuge corridor (Naiman and Dechamps 1997). Existing models to assess river health often rely on the evaluation of existing links between biota and the environment which can take the form of a single biotic element or a multimetric system based on ecologically relevant attributes of the status of assemblages (metrics) that are sensitive to stressors, provides a response that can be separated from natural variation (Barbour et al. 1999).

Results from our study and others conducted on the Lebanese coast suggest that floristic richness as the sole indicator of conservation value of a habitat is unlikely to be sufficient because of recorded low frequency of species distribution (more than $50 \%$ of identified species occur in only one of all sampled sites) (Dagher 2001, Dardas 2000). This noted low frequency pattern, in ours and previous studies, could be a reflection of 
habitat fragmentation which allows for a heterogeneous species composition, primarily consisting of ruderal species adapted to different niches created by high incidence of disturbance. Despite proximity between survey sites, each was unique in the sense that it harbored species different than those observed in other sites; therefore conserving a few sites will not capture the entire array of species diversity because a single representative site in terms of species composition did not exist along the river. In addition, the current species composition along the river may represent an early succession vegetation state of a new community of species adapted to the modified nature of the river. In all cases, the frequency pattern has significant conservation implications and as such management efforts should seek to encompass a combination of sites in order to capture the majority of high conservation value species. The proposed field data collection methodology and organization of floristic information (Table 1) in preparation for RiHAT will enable the identification of unique species and locations along the river.

Species diversity in Ibrahim River was compared to reported values in other river systems. Tabacchi (1995) recorded diversity indices ranging from 4.92-5.99 in $100 \mathrm{~m}^{2}$ sites across a natural river and considered these values as high. Zimmerman et al. (1999) reported indices ranging from 1.61-2.43 along a river system characterized by human induced disturbances. The Shannon index along the riverbanks of the upper Rhine Valley ranged from 1.8-2.9 (Schnitzter 1997). The index range of 0.74-2.844 obtained at Ibrahim River would be considered an average value in comparison to other river systems.

In many instances the characterization of species as weeds, pioneer species, annuals and/or perennials, and exotic species have been used to assess vegetation patterns in relation to specific physical environmental gradients (Howell and Benson 2000; Tabacchi 1995; Zimmerman et al. 1999). Several studies reported increased frequencies of exotic species in response to increased disturbances at the level of river dynamics such as channel disturbances through sedimentation, stream current exposure, and flood frequency (Pabst and Spies 1998, Zimmerman et al. 1999), of human activities (Tabacchi 1995), and of nutrient levels (Howell and Benson 2000). The high percentage of weeds along the river has substantial implications for conservation efforts. Weed presence is indicative of a degraded ecosystem. Even if some of these weed species contribute to riparian function, their negative impacts probably outweigh their contribution to natural biodiversity. Any conservation efforts aimed at rehabilitating the natural riparian vegetation should first and foremost address the issue of weeds (Radosevich et al. 1997).

In this study categorization of the vegetation into weed, invasive, and riparian species was more indicative than total richness as it unveiled increased weed and invasive species with increasing human disturbance specifically identified as agricultural activities which coincided with the down reaches of the river. Nilsson et al. (1989) reported similar findings whereby no clear patterns in species richness were detected along the river except when we considered natural and ruderal species separately. The impact of disturbance on incidence of weedy species has been reported in coastal communities in Lebanon by Abdul Samad (2001) who showed that the percentage of weed species was $14 \%, 22 \%, 30 \%, 47 \%$ in natural, urban, open field agriculture and protected agriculture respectively. With respect to invasive plants, in addition to those species 
recognized globally for their invasive behavior, in semi dry regions, such as the Mediterranean coast of Lebanon, riparian habitats act as refuge for plant species that escape dry and stressful environments to moist and nutrient rich riparian zones. Accordingly the vegetation in these riparian habitats would be expected to consist mostly of nonhabitat specific species that display invasive behavior in such highly favorable environments. Our study confirmed an increased frequency of weed and invasive species which coincided with high human disturbance specifically identified as agriculture.

River conservation can take various forms depending on the objectives and required needs. In setting management targets for riparian ecosystem, the manager and/ or decision maker must first decide on the desired type of ecosystem and the level of protection needed (Hart et al. 1999). Currently, river management projects focus on cost effective environmental approaches whereby an initial quantitative measure of the overall status and health of a river ecosystem constitutes a basis for river management and is based on the concept of prioritization (Verdonschot 2000). Examples of approaches include, restoration to a pre-disturbance state, rehabilitation to a partial structural improvement, functional return to a pre-disturbance state, enhancement to lead to any improvement of a structural or functional attribute of the channel, and dereliction when the river is so degraded or circumstances are not favorable to sustainable improvement that the current state is maintained (Warren and French 2001).

Riparian ecosystems are typically resilient to environmental change by undergoing rapid recovery after moderate level disturbances (Rogers and Biggs 1999). Therefore, any river management attempt should initially consider passive restoration, which involves halting deleterious activities to allow the ecosystem to recover naturally. However, in other circumstances, natural recovery is impossible and more active intervention is required. The developed model takes into consideration the natural resilience of the river and at the same time it relies on other human interventions in situations where the natural capacity of the sites has been exceeded. The desired end state for river management may be represented by scientifically identified endpoints, while to others it may be represented by human values (Rogers and Biggs 1999). Therefore, the developed habitat assessment tool incorporates both ecological and human values in shaping river management strategies.

The tool proposed in this study takes into consideration the floristic and landscape attributes of the survey sites within the study area in order to decide on the appropriate management approach required. In published studies, habitat condition or biological indices are utilized as the basis for either categorizing river sections or for basing their management strategies on these indices. Site index scores from (Stromberg et al. 2006) allowed for placement into one of three condition classes (dry, intermediate and wet) each reflecting particular ranges for site hydrology and vegetation structure. In another study, the derived habitat index was used to place the 35 river reaches of the study into the categories of poor, fair, good, and excellent (Wilhelm et al. 2005). Our tool was developed to produce a habitat condition index to be used for identifying the most appropriate management approach to each section of the river which includes different levels of human intervention. 


\section{Conclusion}

Ibrahim River exemplifies the co-evolution between people and natural resources in the Mediterranean Region where the ecological characteristics of the river can only be explained within the historical and landscape context. The overall habitat index and the distribution a scores across the river contribute to the valuation of the river, beyond established ecosystem services, and may be used as a guideline for management as well as conservation options. The inclusion of a landscape attribute incorporates cultural aspects to the purely biological component of a river and allows for a wider perspective of river conservation and management. This is essential especially when policy decisions by local and national government as well as the private sector and NGO's in Lebanon are increasingly requiring not only accurate but also relevant information about the environment. The developed RiHAT may constitute one practical tool for providing an integrated understanding of the riparian conditions along entire stretches of rivers.

\section{References}

Abdul Samad LF (2001) Environmental analysis of urban and peri-urban agriculture on the Lebanese coastal. MSc. thesis. American University of Beirut.

An KG, Park SS, Shin JY (2002) An evaluation of a river health using the index of biological integrity along with relations to chemical and habitat conditions. Environment International 28: 411-420.

Barbour MT, Swietlik WF, Jackson SK, Courtemanch DL, Davies SP, Yoder CO (2000) The development of integrated methods for assessing river conservation value. Hydrobiologia 422/423: 453-464.

Barbour MT, Gerritsen J, Snyder BD, Stribling JB (1999) Rapid bioassessment protocols for use in streams and wadeable rivers: periphyton, benthic macroinvertebrates and fish, 2nd ed. US Environmental Protection Agency, Office of Water, Washington, D.C.

Bundi U, Peter A, Frutiger A, Hutte M, Liechti P, Sieber U (2000) The development of integrated methods for assessing river conservation value. Hydrobiologia 422/423: 413-428.

Alberta Riparian Habitat Management Society (2002) Alberta lotic wetland health assessment for streams and small rivers user manual. Alberta riparian habitat management program. Lethbridge, Alberta.

Dagher M (2001) Floristic assessment of Lebanese inner coastal communities. MSc thesis. American University of Beirut.

Dardas M (2000) Floristic assessment of Lebanese littoral coastal communities. MSc thesis. American University of Beirut.

Davenport AJ, Gurnell AM, Armitage PD (2004) Habitat survey and classification of urban rivers. River Research Application 20: 687-704.

Davis SD, Heywood VH, Hamilton AC (1994) Centers of plant diversity: A guide and strategy for their conservation. Vol.1. The World Wide Fund for Nature and IUCN-World Conservation Union. Switzerland. 
Edgecombe WS (1970) Weeds of Lebanon. American University of Beirut. Lebanon.

El Hachem C (2000) Insect diversity along the Lebanese Coast in selected plant communities.

MSc. thesis. American University of Beirut.

Environmental Protection Agency-EPA (1996) Biological criteria: technical guidance for streams and small rivers. Chapter 5: Evaluating environmental effects.

Fitzpatrick A, Fox J, Leung KY (2001). Environmental baseline survey of Nahr Ibrahim. Lebanon. Hart BT, Maher B, Lawrence I (1999) New generation water quality guidelines for ecosystem protection. Freshwater Biology 41: 347-359.

Hepper N, Zahreddine H (2000) Annotated checklist of Lebanese coastal plants. Royal Botanic Gardens, Kew. American University of Beirut, Lebanon.

Howell J, Benson D (2000) Predicting potential impacts of the environment flows on weedy riparian vegetation of the Hawkesbury-Nepean River, southeastern Australia. Austral Ecology 25: 463-475.

Hughes RM (1995) Defining Acceptable Biological Status by Comparison with Reference Conditions. Biological Assessment and Criteria: Tools for Water Resource Planning and Decision Making. Lewis Publishers, Boca Raton, Florida, USA.

IUCN (2000) List of threatened species. http://www.iucnredlist.org/

Jansen A, Robertson AI (2001) Relationships between livestock management and the ecological condition of riparian habitats along an Australian floodplain river. Journal of applied ecology 38: 63-75

Kasyak (1996) Maryland Biological Stream Survey. Physical Habitat: Chapter 7. http://www. dnr.state.md.us/streams/mbss/ea99-6_toc.html

Kent M, Coker P (1992) Vegetation description and analysis: A practical approach. CRC Press, Boca Raton.

Khouzami M, Bassil M, Fortunat L, Hayek A (1996) Etude de la diversité biologique du Liban. Ministry of Agriculture: UNEP. Lebanon.

Kleynhans CJ (1999) Resource directed measures for protection of water resources: River ecosystems. Institute for water quality studies. Department of Water Affairs and Forestry. South Africa. http://www.wrc.org.za/wrcrdm/wrcrivers/riv_appR3_version1.0.doc

Ladson AR, White LJ, Doolan JA, Finlayson BL, Hart BH, Lake PS, Tilleard JW (1999) Development and testing of an index of stream condition for waterway management in Australia. Freshwater Biology 41: 453-468.

Le Floc'H E (1991) Invasive plants of the Mediterranean basin. In: Groves RH, di Castri F(Eds) Biogeography of Mediterranean invasions. Cambridge University Press.

Maddock I (1999) The importance of physical habitat assessment for evaluating river health. Freshwater Biology 41: 373-391.

Ministry of Agriculture (1999) Site-pilote No II-Jabal Moussa: plan de gestion durable. Office National des forets, Lebanon.

Ministry of Environment-Lebanon (2001) http://www.moe.gov.lb/

Mouterde P (1970) Nouvelle flore du Liban et de la Syrie. 3 tomes textes. 3 tomes atlas. Dar El-Machreq, Beirut.

Myers N, Mittermeier RA, Mittermeier CG, Da Fonseca GAB, Kent J (2000) Biodiversity Hotspot for Conservation Priorities. Nature 403: 853-858. 
Naiman R, Decamps H (1997) The ecology of interferes: riparian zones. Ann. Rev. Ecol. Syst. 28: 621-658.

Nilsson C, Grelsson G, Johansson M, Sperens U (1989) Patterns of plant species richness along riverbanks. Ecology 70: 77-84.

Oliveira SV, Cortes RMV (2005) A biologically relevant habitat condition index for streams in northern Portugal. Aquatic Conservation: Marine and Freshwater Ecosystems 15: 189210.

Olson C, Harris R (1997) Applying a Two Stage System for Prioritizing Riparian Restoration at San Luis Rey River, San Diego County, California. Restoration Ecology 5(4S): 43-55.

O’Neill MP, Schmidt JC, Dobrowolski JP, Hawkins CP, Neale CMU (1997) Identifying Sites for Riparian Wetland Restoration: Application of a Model to the Upper Arkansas River Basin. Restoration Ecology 5(4S): 85-102.

Pabst RT, Spies A (1998) Distribution of herbs and shrubs in relation to landform and canopy cover in riparian forests of coastal Oregon. Canadian Journal of Botany 76: 298-315.

Papazian HS (1981) A hydrological study of the Nahr Ibrahim Basin in the vicinity of the paper mill project of Indevco in Lebanon. Lebanon.

Post GE, Dinsmore JE (1933) Flora of Syria, Palestine, and Sinai Volume I-II Second Edition. American University Press, Beirut.

Radosevich S, Holt J, Ghersa C (1997) Weed Ecology: Implications for Management. John Wiley \& Sons, Inc., New York.

Raven PJ, Holmes NTH, Dawson FH, Fox PJA, Everard M, Fozzard IR, Rouen KJ (1998) River Habitat Quality: the physical character of rivers and streams in UK and Isle of Man. Environment Agency, Bristol.

Rogers K, Biggs H (1999) Integrating indicators, endpoints and value systems in strategic management of the rivers of the Kruger National Park. Freshwater Biology 41: 439-451.

Rossi E, Kuitunen M (1996) Ranking of habitat for the assessment of ecological impact in land use planning. Biological Conservation 77: 227-234.

Russell GD, Hawkins CP, O’Neill MP (1997) The Role of GIS in Selecting Sites for Riparian Restoration Based on Hydrology and Land Use. Restoration Ecology 5(4S): 56-68.

Schnitzler A (1997) River dynamics as a forest processes: interaction between fluvial systems and alluvial forests in large Europeans river plains. The Botanical Review 63(1): 39-64.

Simon TP, Stewart PM, Rothrock PE (2001) Development of multimetric indices of biotic integrity for riverine and palustrine wetland plant communities along Southern Lake Michigan. Aquatic Ecosystem Health and Management 4: 293-309

Sorensen T (1948) A method of establishing groups of equal amplitude in plant sociology based on similarity of species content. Biologiske Skrifter 5(4): 1-34.

Stromberg JC, Lite SJ, Rychener TJ, Levick LR, Dixon MD, Watts JM (2006) Status of the riparian ecosystem in the upper San Pedro river, Arizona: application of an assessment model. Environmental Monitoring and Assessment 115: 145-173.

Tabacchi E (1994) Structural variability and invasions of pioneer plant communities in riparian habitats of the middle Adour River (SW France). Canadian Journal of Botany 73: 33-44.

Texas Natural Resource Conservation Commission-TNRCC (1999) Chapter 8: Stream habitat assessment procedures. http://www.tnrcc.state.tx.us/admin/topdoc/gi/252/chap08.pdf 
Thompson K, Hodgson JG, Gaston KJ (1998) Abundance-range size relationships in the herbaceous flora of central. Journal of Ecology 86: 439-448.

Tiner R, Starr M, Bergquist H, Swords J (2000) Watershed-based wetland characterization for Maryland's Nanticoke river and costal bays watersheds: A preliminary assessment report. Maryland Department of Natural resources, Annapolis.

USDI (1998) Riparian Area Management: Process for assessing proper functioning condition. U.S. Department of Interior Bureau of Land Management TR-177-9.

Verdonschot PFM (2000) Integrated ecological assessment methods as a basin for sustainable catchment management. Hydrobiologia 422/423: 389-412.

Warren CE (1979) Toward classification and rationale for watershed management and stream protection. Oregon State University. United States.

Warren A, French JR (2001) Habitat Conservation: Managing the Physical Environment. John Wiley \& Sons, New York.

Wilhelm JGO, Allan JD, Wessell KJ, Merritt RW, Cummins KW (2005) Habitat Assessment of Non-Wadeable Rivers. Michigan Environmental Management 36(4): 592-609.

Wolz KD (1998) Protection and remediation of rivers and river landscapes in the Republic of Lebanon volume one (report). Ministry of Environment, Lebanon.

Zimmerman JC, DeWald LE, Rowlands PG (1999) Vegetation diversity in an interconnected ephemeral riparian system of north-central Arizona, USA. Biological Conservation 90: 217-228.

Zahreddine H (2001) Plant distribution, genetic characteraization and horticultural applications for the conservation management of two coastal plant species in Lebanon. MSc thesis. American University of Beirut. 